\title{
Bio-physical characteristics of gastrointestinal mucosa of celiac patients: comparison with control subjects and effect of gluten free diet-
}

\author{
Stefania Bertolazzi ${ }^{1}$, Francesco Lanzarotto ${ }^{1}$, Barbara Zanini ${ }^{1}$, Chiara Ricci ${ }^{1}$, Vincenzo Villanacci ${ }^{2}$ and \\ Alberto Lanzini ${ }^{*}$
}

\begin{abstract}
Background: Intestinal mucosa is leaky in celiac disease (CD), and this alteration may involve changes in hydrophobicity of the mucus surface barrier in addition to alteration of the epithelial barrier. The aims of our study were i) to compare duodenal hydrophobicity as an index of mucus barrier integrity in CD patients studied before ( $n=38)$ and during gluten- free diet (GFD, $n=68)$, and in control subjects $(n=90)$, and ii) to check for regional differences of hydrophobicity in the gastro-intestinal tract.

Methods: Hydrophobicity was assessed by measurement of contact angle (CA) (Rame Hart 100/10 goniometer) generated by a drop of water placed on intestinal mucosal biopsies.

Results: CA (mean \pm SD) of distal duodenum was significantly lower in CD patients $\left(56^{\circ} \pm 10^{\circ}\right)$ ) than in control subjects $\left(69^{\circ} \pm 9^{\circ}, p<0.0001\right)$, and persisted abnormal in patients studied during gluten free diet $\left(56^{\circ} \pm 9^{\circ} ; p<\right.$ 0.005). CA was significantly higher $\left(62^{\circ} \pm 9^{\circ}\right)$ in histologically normal duodenal biopsies than in biopsies with Marsh $1-2\left(58^{\circ} \pm 10^{\circ} ; p<0.02\right)$ and Marsh 3 lesions $\left(57^{\circ} \pm 10^{\circ} ; p<0.02\right)$ in pooled results of all patients and controls studied. The order of hydrofobicity along the gastrointestinal tract in control subjects follows the pattern: gastric antrum $>$ corpus $>$ rectum $>$ duodenum $>$ oesophagus $>$ ileum.

Conclusions: We conclude that the hydrophobicity of duodenal mucous layer is reduced in CD patients, and that the resulting decreased capacity to repel luminal contents may contribute to the increased intestinal permeability of CD. This alteration mirrors the severity of the mucosal lesions and is not completely reverted by gluten-free diet. Intestinal hydrophobicity exhibits regional differences in the human intestinal tract.
\end{abstract}

\section{Background}

The intestinal barrier is an important defence mechanism to prevent the spreading of bacteria and toxins of different origin from intestinal lumen to the systemic circulation [1]. It consists of the epithelial barrier, an anatomical barrier between the luminal content and the host, and of the pre-epithelial barrier, a functional barrier mainly constituted of a mucus layer and by other factors such as the trefoil peptides, defensins and secretory IgA. The importance of the mucus layer as a component of the pre-epithelial barrier is supported by a

\footnotetext{
* Correspondence: lanzini@med.unibs.it

'Gastroenterology Unit: Spedali Civili and University. Piazzale Spedali Civili 1. 25123 Brescia. Italy

Full list of author information is available at the end of the article
}

large body of evidence in humans and in the animal in studies showing a protective effect against injury in the stomach $[2,3]$, and a capacity to prevent bacteria and luminal toxins to come into direct contact with intestinal epithelium [4].

The intestinal barrier is altered in several diseases including celiac disease (CD) [5] an autoimmune disease that develops in genetically predisposed subjects exposed to ingestion of wheat gliadin and of related prolamines of barley and rye. This alteration of the intestinal barrier of CD results in increased intestinal permeability [6], a phenomenon attributed to excess production of a local peptide, zonulin, leading to disassembly of the tight junction structure that in physiological conditions seals the barrier and limits the paracellular passage of

\section{Ciomed Central}


macromolecules, including the toxic fractions of gliadin [7]. This pathogenetic mechanism and the subsequent sub-epithelial events leading to intraepithelial lymphocytic infiltration and to mucosal atrophy have been extensively studied [8], but limited information is available on events involving the pre-epithelial component of the intestinal barrier, namely the mucous layer.

One way of assessing the functional integrity of the mucus layer is by measuring its hydrophobicity, a surface bio-physical property that affects adhesion of macromolecules, bacteria and toxins to the intestinal epithelia $[9,10]$. The importance of this characteristic in contributing to the integrity of the intestinal barrier is supported by the finding that decreased hydrophobicity has been documented in a variety of conditions including peptic ulcer disease [11], Helicobacter pylori infection and gastritis [12], and to accompany damage to the stomach or colon caused by non steroidal anti-inflammatory drugs [13], 2,4,6-trinitrobenzenesulphoric acid [14], LPS [15] or dextran sodium sulphate [16].

Mucosal hydrophobicity can be assessed by an empirical thermodinamic approach involving measurement of the contact angle subtended at the triple point where the solid-liquid, liquid-air and solid air interfaces meet following application of a drop of fluid to a solid surface [2]. The principle behind this technique is that a drop of fluid tend to form beads when applied on hydrophobic surfaces forming high contact angles at the triple point interface, and to spread on hydrophilic surfaces forming a small contact angle. Thus the higher is the contact angle the more hydrophobic is the surface.

The aim of our study was to assess the hyfrophobicity of the mucus barrier by measuring contact angle of gastro-intestinal mucosa exposed to a drop of saline in CD patients at diagnosis, and to assess the effect of gluten free diet (GFD). We also studied control subjects to obtain reference values of surface hydrophobicity of different regions of the gastro-intestinal tract in healthy humans. Preliminary validation studies were carried out to assess optimal experimental conditions and reproducibility.

\section{Methods}

We collected mucosal biopsies at endoscopy in 3 different groups of patients consecutively recruited from December 2004 to January 2007. The first group consisted of control subjects referred to our Gastroenterology Unit for clinical and endoscopic evaluation. In all cases no abnormality was detected at endoscopy or histology except for minimal changes, and in all cases the final diagnosis was of functional disease. The second group consisted of $C D$ patients diagnosed on the basis of positive anti- $t$-transglutaminases and/or antiendomysial antibodies and of a characteristic duodenal lesion.
The third group consisted of CD patients on GFD for at least 1 year undergoing follow-up endoscopy, a standard procedure in our CD Clinic [17]. In these latter group adherence to GFD was assessed by interview using a 4 point Likert scale as previously described [18].

Following endoscopic examination biopsy specimens were taken $1 \mathrm{~cm}$ above the $\mathrm{Z}$ line in the oesophagous, 1 $\mathrm{cm}$ above the lesser curve and within $2 \mathrm{~cm}$ of the pylorus in the stomach, and at midway along the descending duodenum. Biopsies in the rectum were collected at $10 \mathrm{~cm}$ from the anal verge, and in the terminal ileum at $5 \mathrm{~cm}$ from the ileo-cecal valve. Biopsies were placed mucosal up on a piece of cellulose disk, and 1 unfixed biopsy specimen from each region was used for measurement of mucosal hydrophobicity by goniometry. Two more biopsies ( 4 in the case of duodenal biopsies) were fixed with formalin for subsequent histological examination.

Sections for histological examination were stained with $H \& E$ and presence and severity of inflammation was graded according to standard criteria. Duodenal biopsies have been graded according to modified Marsh classification $[19,20]$, and immnuohistochemistry has been used to identify and count CD3+ intraepithelial lymphocytes.

For goniometry, freshly collected biopsy specimens oriented mucosal up were immediately washed with saline and placed on the stage of the goniometer (Rame/ Hart 100/00 NJ, USA) fitted with a monochromatic light source and micrometer-activated syringe (Rame-Hart 100-10) for applying $5 \mu \mathrm{L}$ of $0.15 \mathrm{M}$ saline to the biopsy surface [21]. On application of the water drop two cross-hairs fitted within the microscope of the goniometer were aligned to the tangent of the air-saline drop-biopsy interface and the contact angle read off a scale incorporated in the eyepiece of the goniometer. All goniometric measurements have been carried out by one of us (SB) unaware of the site of biopsies and of endoscopic findings. The value of each measurement was the mean of 3 contact angle readings.

\section{Validation studies}

The effect of drying of mucosal biopsies on CA measurements was assessed by allowing biopsies to air dry at room temperature after gentle washing, and by measuring contact angle at 10 min intervals starting from 10 minutes after collection. Reproducibility of CA measurements by the same goniometrist was assessed by calculating coefficient of variation of multiple measurements on biopsy specimens.

\section{Statistics}

Results are expressed as means \pm SD and as upper and lower $95 \%$ Confidence Interval of the mean. Unpaired $t$ 
test was carried out for comparisons, and a p value < 0.05 was taken to indicate statistical significance for differences.

The study has been carried out in compliance with the Helsinki Declaration following approval by our Institutional Ethics Committee, and patients have signed an informed consent to the study.

\section{Results}

Thirty-eight newly diagnosed CD patients on gluten containing diet, $68 \mathrm{CD}$ patients on GFD and 105 controls (69 for upper and 36 for both upper and lower gastrointestinal tract studies) participated to the study. Anthropometric, serological and histological characteristics of patients and controls are summarized in table 1. All CD patients studied on gluten containing diet tested positive at CD related serology, and duodenal biopsy showed villous atrophy in 33 and lymphocytic duodenosis in 5. All patients studied on GFD given for $29 \pm 10$ months (range 12-35 months) were strictly adherent to GFD as assessed by interview, and all tested negative at CD related serology. Duodenal histology demonstrated persistent lymphocytic duodenosis in 60 patients, and mild villous atrophy in 5 . No one of the control subjects

Table 1 anthropometric and clinical characteristics of celiac patients studied at baseline, of patients studied during gluten free diet and of control subjects

\begin{tabular}{|c|c|c|c|}
\hline \multirow[t]{2}{*}{ Upper Gl tract } & \multicolumn{2}{|r|}{ Celiacs } & \multirow[t]{2}{*}{ Controls } \\
\hline & Baseline & GFD & \\
\hline $\mathrm{n}$ & 38 & 68 & 69 \\
\hline $\mathrm{F} / \mathrm{M}$ & $27 / 11$ & $49 / 19$ & $50 / 19$ \\
\hline age (years) & $34.5 \pm 4.7$ & $36.2 \pm 2.2$ & $48.9 \pm 16.4^{*}$ \\
\hline \multicolumn{4}{|l|}{ Marsh } \\
\hline 0 & 0 & 2 & 57 \\
\hline 1 & 0 & 0 & 3 \\
\hline 2 & 5 & 60 & 8 \\
\hline $3 a$ & 5 & 5 & 0 \\
\hline $3 b$ & 5 & 1 & 0 \\
\hline $3 c$ & 23 & 0 & 0 \\
\hline \multicolumn{4}{|l|}{ Antibodies (n) } \\
\hline $\mathrm{tTg}$ & 17 & 0 & 0 \\
\hline EMA & 13 & 0 & 0 \\
\hline $\mathrm{t}-\mathrm{TG}+\mathrm{EMA}$ & 8 & 0 & 0 \\
\hline \multicolumn{4}{|l|}{ HP (n) } \\
\hline positive & 8 & 10 & 13 \\
\hline negative & 30 & 58 & 56 \\
\hline Upper and lower GI tract & & & Controls \\
\hline $\mathrm{n}$ & & & 36 \\
\hline $\mathrm{F} / \mathrm{M}$ & & & $21 / 15$ \\
\hline age (years) & & & $51.6 \pm 20.5^{*}$ \\
\hline
\end{tabular}

Biopsies of the lower gastrointestinal tract have been obtained in control subjects only. GFD = gluten free $\operatorname{diet} \mathrm{Gl}=$ gastrointestinal. ${ }^{*}=p<0.0001$ tested positive at anti- $\mathrm{t}$-transglutaminases antibodies serological screening.

\section{Validation studies (figure 1)}

The effect of mucosal drying on goniometric measurements was studied in 15 gastric, 12 duodenal and 12
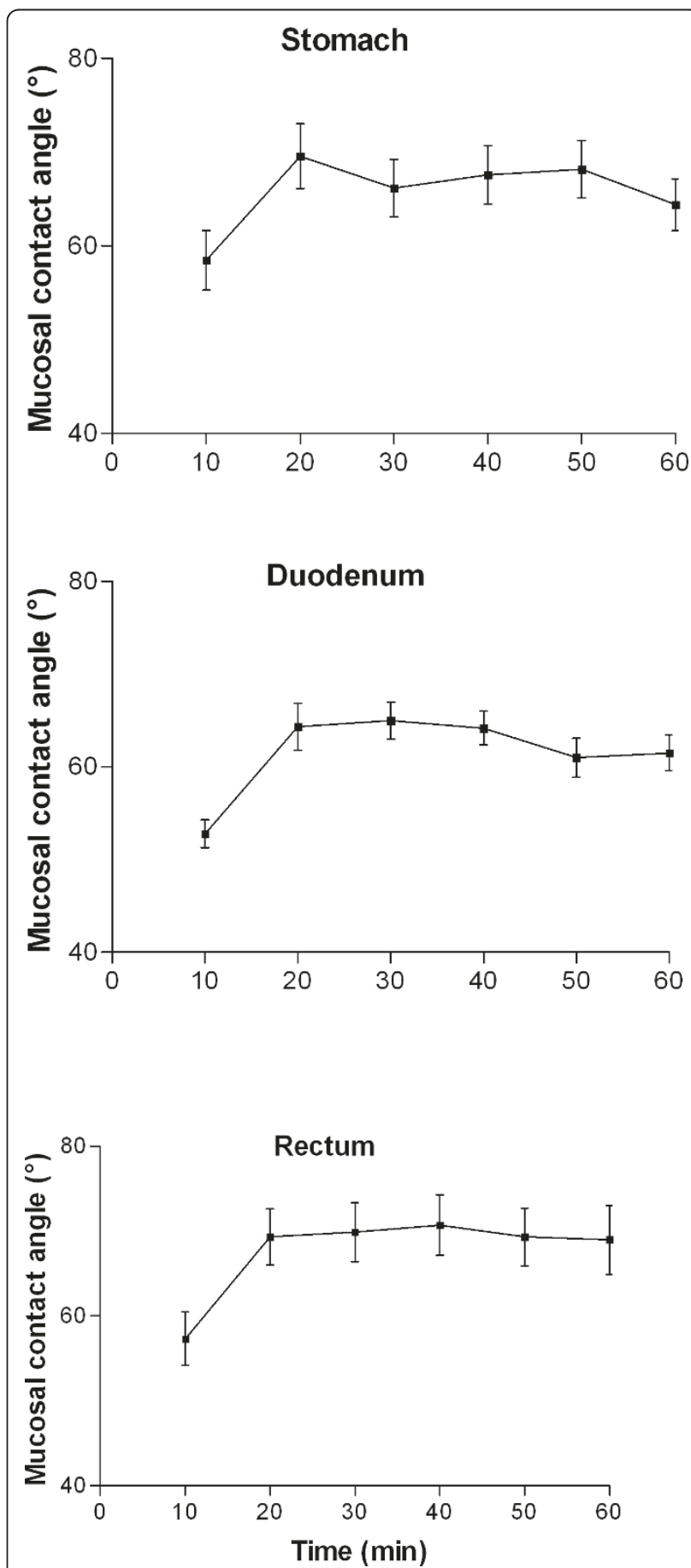

Figure 1 Validation study: effect of mucosal drying on gastric, duodenal and rectal mucosal contact angle. 
rectal biopsies. Contact angle increased in gastric biopsies from $59^{\circ} \pm 4^{\circ}$ at time 10 minutes to $72^{\circ} \pm 4^{\circ}$ at time 20 minutes and remained stable thereafter at time 30 $\left(68^{\circ} \pm 3^{\circ}\right), 40\left(72^{\circ} \pm 4^{\circ}\right), 50\left(70^{\circ} \pm 3^{\circ}\right)$ and 60 minutes $\left(67^{\circ} \pm 3^{\circ}\right)$. Similar pattern with early increase in value and a plateau effect after 20 minutes was observed for biopsies taken in the duodenum $\left(53^{\circ} \pm 2^{\circ}, 64^{\circ} \pm 3^{\circ}, 65^{\circ}\right.$ $\pm 2^{\circ}, 65^{\circ} \pm 2^{\circ}, 61^{\circ} \pm 2^{\circ}$ and $61^{\circ} \pm 2^{\circ}$ at time 10, 20, 30, 4050 and 60 minutes respectively) and in the rectum $\left(57^{\circ} \pm 3^{\circ}, 69^{\circ} \pm 3^{\circ}, 70^{\circ} \pm 2^{\circ}, 71^{\circ} \pm 4^{\circ}, 69^{\circ} \pm 3^{\circ}\right.$ and $69^{\circ} \pm$ $4^{\circ}$ at time 10, 20, 30, 4050 and 60 minutes respectively). Coefficient of variation for 5 CA readings in 6 biopsy specimens of gastric corpus was $8 \%, 3 \%, 5 \%, 2 \%, 2 \%$ and $5 \%$, respectively.

Based on these validation results all subsequent measurements of contact angle were carried on mucosal biopsies within 20-60 min from collection following gentle biopsy washing with saline.

\section{Surface hydrophobicity in celiac disease and effect of gluten free diet (figures 2, 3)}

Contact angle of duodenal biopsies (Figure 2) was significantly lower in $\mathrm{CD}$ patients $\left(56^{\circ} \pm 10^{\circ}\right.$ : $95 \% \mathrm{CI}$ : $\left.53^{\circ}-60^{\circ}\right)$ than in healthy subjects $\left(65^{\circ} \pm 7^{\circ}: 95 \%\right.$ CI: $63^{\circ}-67^{\circ}: p<$ $0.0001)$, and remained virtually unchanged in $C D$ patients during GFD $56^{\circ} \pm 9^{\circ}\left(95 \%\right.$ CI: $54^{\circ}-59^{\circ}$; $\mathrm{p}=$ $0.904)$. Contact angle of duodenal mucosa was not affected by Helicobacter pylori infection in CD patients $\left(57^{\circ} \pm 10^{\circ}\right.$ vs $\left.52^{\circ} \pm 11^{\circ}\right)$, CD patients on GFD $\left(57^{\circ} \pm 9^{\circ}\right.$ vs $\left.55^{\circ} \pm 9^{\circ}\right)$ and controls $\left(61^{\circ} \pm 10^{\circ}\right.$ vs $65^{\circ} \pm 10^{\circ}$ for Helicobacter pylori negative and positive, respectively)

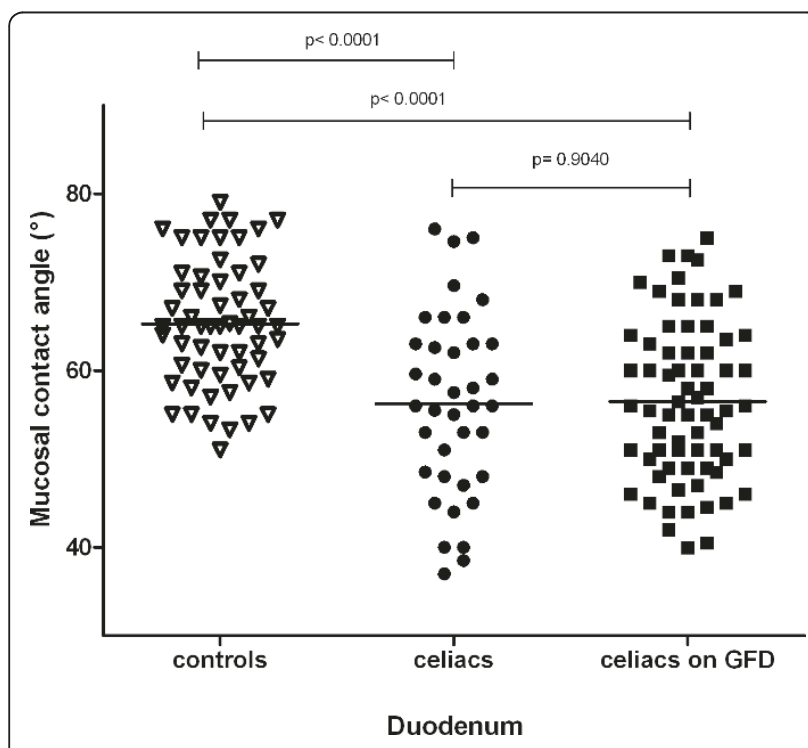

Figure 2 Contact angle of duodenal mucosa in control subjects, celiac patients and celiac patients on gluten-free-diet GFD = gluten free diet.

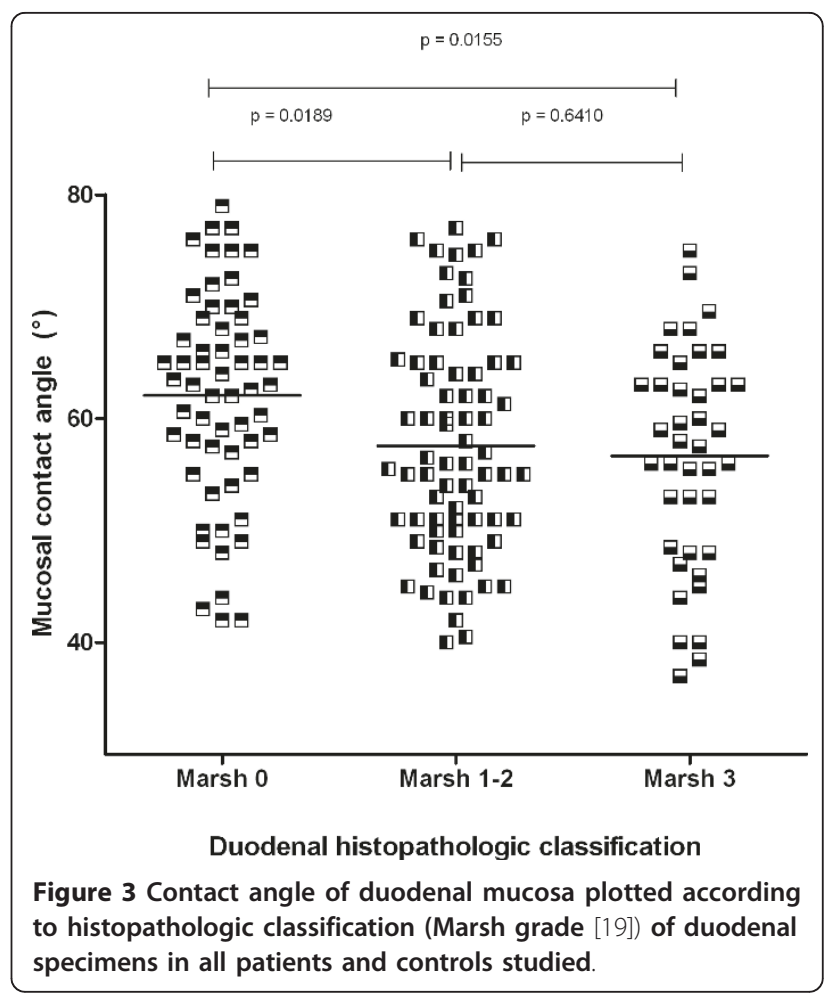

and was not related to gender or age in all 3 groups (Pearsons' $r=0.02781$ for $C D, r=0.1157$ for $C D$ on GFD and $r=0.0883$ for controls).

By contrast with results in duodenal biopsies, there was no difference in contact angle measurements on antral biopsies between $\mathrm{CD}$ patients $\left(69^{\circ} \pm 9^{\circ}\right.$; $95 \% \mathrm{CI}$ : $\left.65^{\circ}-72^{\circ}\right)$, CD patients during GFD $\left(68^{\circ} \pm 10^{\circ} ; 95 \% \mathrm{CI}\right.$ : $\left.66^{\circ}-71^{\circ}\right)$ and control subjects $72^{\circ} \pm 8^{\circ}\left(95 \%\right.$ CI: $\left.70^{\circ}-73^{\circ}\right)$, and there was also no difference on biopsies taken from gastric corpus the 3 groups $\left(70^{\circ} \pm 9^{\circ} ; 95 \% \mathrm{CI}\right.$ : $68^{\circ}-71^{\circ} / /$ $67^{\circ} \pm 10^{\circ}$; $95 \%$ CI: $63^{\circ}-71^{\circ} / / 67^{\circ} \pm 10^{\circ}$; $95 \%$ CI: $65^{\circ}-70^{\circ}$, respectively).

Figure 3 shows results of contact angle measured on duodenal mucosa plotted independently of clinical diagnosis as a function of histopathologic characteristics of the mucosa in all 175 patients in the 3 groups involved in the study. Contact angle was higher in mucosal biopsies classified as Marsh $0\left(62^{\circ} \pm 9^{\circ} ; 95 \%\right.$ CI: $60^{\circ}-64^{\circ}: \mathrm{p}<$ $0.0001)$ than in those classified as Marsh $1-2\left(58^{\circ} \pm 10^{\circ}\right.$; $95 \%$ CI: $\left.55^{\circ}-60^{\circ}: \mathrm{p}=0.0189\right)$ and as Marsh $3\left(57^{\circ} \pm 10^{\circ}\right.$; $95 \%$ CI: $\left.54^{\circ}-60^{\circ}: \mathrm{p}=0.0155\right)$.

Regional differences in surface hydrophobicity (figures 4 and 5)

Regional differences for CA measurement were present along the gastro-intestinal tract in control subjects (Figure 4). CA was $51^{\circ} \pm 11^{\circ}\left(95 \% \mathrm{CI}: 45^{\circ}-50^{\circ}\right)$ in 67 oesophageal, $70^{\circ} \pm 9^{\circ}\left(95 \% \mathrm{CI}: 68^{\circ}-71^{\circ}\right)$ in 90 gastric body, 


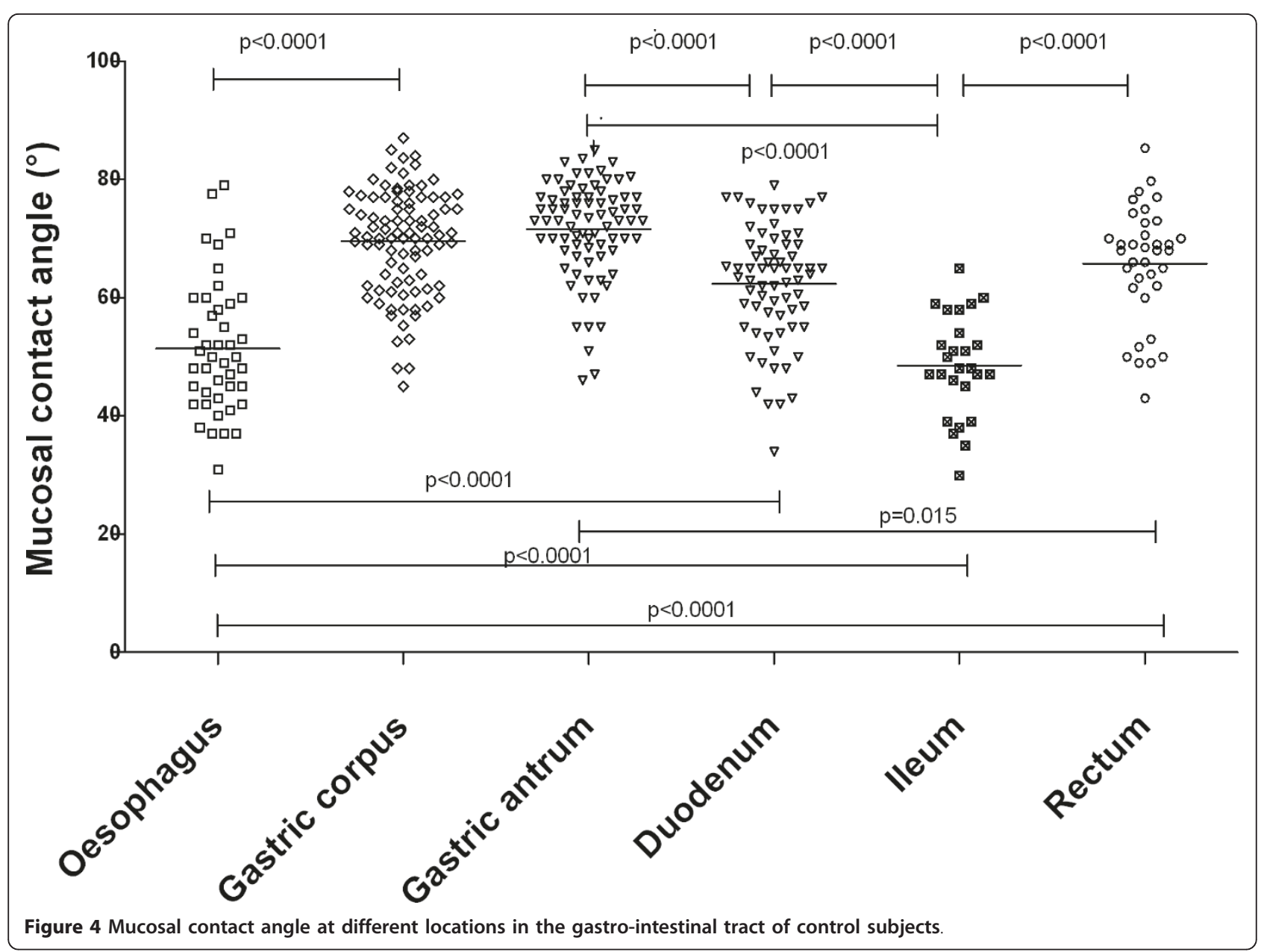

$72^{\circ} \pm 8^{\circ}\left(95 \%\right.$ CI: $\left.70^{\circ}-73^{\circ}\right)$ in 78 gastric antrum, $62^{\circ} \pm$ $10^{\circ}\left(95 \% \mathrm{CI}: 60^{\circ}-65^{\circ}\right)$ in 69 duodenal, $49^{\circ} \pm 9^{\circ}(95 \% \mathrm{CI}$ $\left.45^{\circ}-52^{\circ}\right)$ in 26 distal ileum and $66^{\circ} \pm 10^{\circ}$ (95\% CI: $63^{\circ}$ $\left.-69^{\circ}\right)$ in 36 rectal biopsies.

Regional differences for CA measurement were maintained in $C D$ patients in studies limited to the upper gastro-intestinal tract (Figure 5). CA was lower on oesophageal $\left(40^{\circ} \pm 7^{\circ}\left(95 \% \mathrm{CI}: 37^{\circ}-43^{\circ}\right)\right.$ than on gastric antral biopsies $\left(69^{\circ} \pm 9^{\circ}\left(95 \% \mathrm{CI}: 65^{\circ}-72^{\circ}\right)\right.$. CA of duodenal biopsies $\left(56^{\circ} \pm 10^{\circ}\left(95 \% \mathrm{CI}: 53^{\circ}-60^{\circ}\right)\right.$ was lower than that of gastric antral $69^{\circ} \pm 9^{\circ}\left(95 \%\right.$ CI: $\left.65^{\circ}-72^{\circ}: \mathrm{p}<0.0001\right)$ and corpal biopsies $56^{\circ} \pm 10^{\circ}\left(95 \% \mathrm{CI}: 53^{\circ}-60^{\circ}: \mathrm{p}<\right.$ $0.0001)$. Similar results have been obtained in CD patients during GFD with lower values for contact angle in duodenal $56^{\circ} \pm 9^{\circ}\left(95 \% \mathrm{CI}: 54^{\circ}-59^{\circ}\right)$ than in gastric antral $69^{\circ} \pm 10^{\circ}\left(95 \%\right.$ CI: $66^{\circ}-71^{\circ}: \mathrm{p}<0.0001$ and corpal biopsies $67^{\circ} \pm 10^{\circ}\left(95 \% \mathrm{CI}: 65^{\circ}-70^{\circ}\right.$ : p < 0.0001).

\section{Discussion}

In the present study we assessed surface hydrophobicity of gastrointestinal mucosa as an index of the functional integrity of the mucus layer, a layer that acts as a "closing seal"[22] of the intestinal barrier. This bio-physical characteristic can be studied by measuring contact angles formed by sessile water droplets placed on freshly collected biopsies. The interrelation between contact angle and surface energy assumes that the surface on which contact angle is measured is smooth and homogenous [23], and this is obviously not the case for mucosal biopsies. Furthermore, drying, presence of debris and trauma of biopsy collection may cause non-physiological changes. Although these observations are a matter of concern, drying has been reported by Hills [24] to provide a more conservative estimate of the energy reduction that would occur if the mucus remained in the physiological hydrated state. Our validation study confirms that contact angle increases during mucosal drying to a point when it remains stable and reproducible up to at least $60 \mathrm{~min}$ following biopsy collection.

The main aspect of our study is that we assessed the hydrophobicity of the duodenal mucus barrier in CD patients studied at diagnosis and in CD patients on GFD. This assessment was prompted by a large body of 


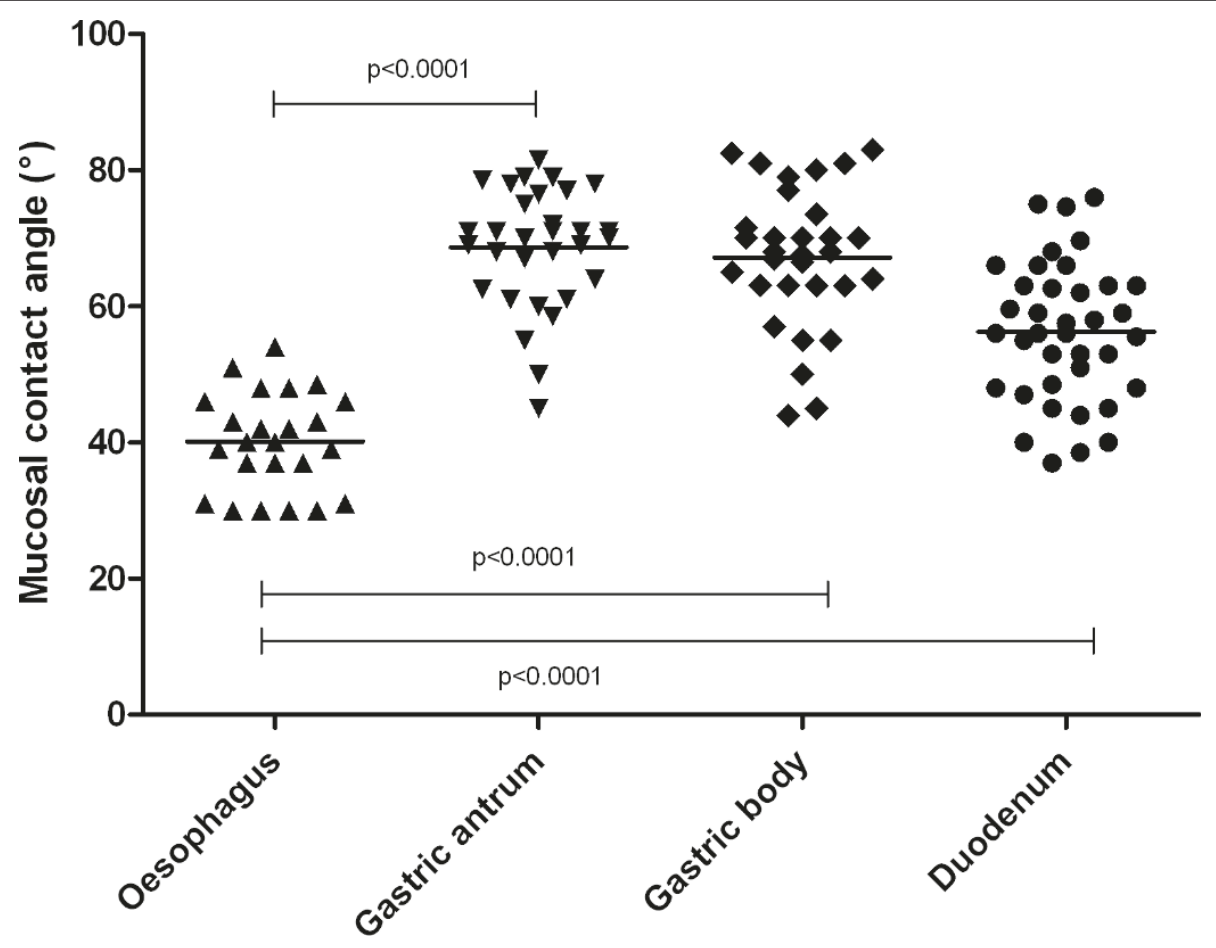

Figure 5 Mucosal contact angle at different locations in the gastro-intestinal tract of celiac patients.

evidence indicating that intestinal permeability to macromolecules is increased in CD patients $[6,25,26]$. This phenomenon has been extensively studied in relation to the epithelial component of the intestinal barrier, and shown to involve altered regulation of the tight junctions that provide contiguity of epithelial cells and regulate the traffic trough the paracellular pathway. Zonulin has been identified as a protein with capacity to disassemble TJ [7] as an early event in the development of CD [27] favouring the passage of gliadin toxic fragments via the paracellular pathway from the intestinal lumen to the submucosa. Although the validity of this model has been questioned [28], the pathogenetic role of increased permeability in development of $\mathrm{CD}$ is firmly established.

Our study clearly indicates that the mucus barrier is altered in $\mathrm{CD}$, and that this defect is not restored to normal during GFD as indicated by the observation that hdyrophobicity of duodenal mucosa is lower in CD patients than in control subjects, and that this abnormality persists during GFD. These differences cannot be accounted by artefacts due to Helicobacter pylori infection and by differences in age, as reported by others for gastric biopsies [29], because there was no relationship in our patients and in controls between these parameters and duodenal CA. Furthermore, the younger age of our CD compared with controls should point, if anything, to a higher $\mathrm{CA}$, an opposite effect of what we have found.
The reduced hydrophobicity is specific for duodenal mucosa in $\mathrm{CD}$, as indicated by the finding that hydrophobicity of gastric mucosa was similar in $\mathrm{CD}$ patients and in controls.

The mechanism involved in this bio-physical alteration of the duodenal mucus barrier is unclear. Previous studies have reported alteration of the structure of duodenal mucus in CD patients associated with defect of the trefoil factors family [30] and with the structure and secretory pattern of mucus glycoprotein [31], defects that may affect stability of mucus. We could not further investigate the mechanism involved in reduced hydrophobicity of duodenal mucus barrier, but it is clear from our results a relationship with the anatomical changes of the mucosa, independently of clinical diagnosis. This is suggested by our finding that by plotting together results of duodenal CA obtained in control subjects with those obtained in CD patients off and on GFD, there was a clear-cut dependency of reduced mucus hydrophobicity on severity of duodenal histopathology (Figure 3). This was irrespective of clinical diagnosis because the group with normal histology comprised CD patients on GFD in addition to control subjects, and the group with Marsh-1-2 lesion comprised normal subjects in addition to $C D$ patient on or off GFD. On the basis of our results we cannot firmly establish the nature of this relationship, and although a cause-effect mechanism cannot be proven it seems to 
us plausible because of the independence of the aetiology of mucosal damage.

To what extent the alteration in mucus barrier contributes to the pathogenesis of $C D$, and whether this alteration is a primary defect is totally unclear but it fits a paradigm for initiation of autoimmune diseases proposed by Arrieta et al [5]. According to this model, undigested gliadin fractions are kept separate from subepithelial immune system by a competent intestinal barrier. Disease activation occurs when factors with capacity of altering the intestinal barrier integrity favour paracellular transit of toxic fractions of gliadin, and these initiating factors include drugs such as NSAIDs or infections that are all well known factors for their capacity to disrupt the mucus barrier $[13,32,33]$. The late onset of CD in genetically predisposed subjects fits with this hypothesis on the role of initiating factors.

Another aspect of our study is that we looked at regional differences of hydrophobicity of intestinal mucosa in controls and in CD, and found marked differences in different intestinal regions. These differences are qualitatively similar to those reported by Spychal et al [21] in humans showing high hydrophobicity in gastric and in rectal mucosa, with lower values in the duodenum and in the ileum. This regional difference is common to many mammalian species $[10,16,21,34,35]$ although slight species-related differences occur. By contrast with results in the animal, in our study mucosal hydrophobicity was lower in the distal ileum than in the duodenum. No other study to our knowledge has reported results for hydrophobicity of distal ileum in humans, but the tendency for hydrophobicity to be reduced from proximal to distal duodenum reported by Spychal [21] in healthy subjects is consistent with our results. The low hydrophobicity in the oesophagus observed in our study is also novel, and explains the susceptibility of oesophageal mucosa to refluxed gastric acid because hydrophobicity is important in repelling the diffusion of hydrogenions [2] from coming in contact with the epithelial cells.

\section{Conclusions}

In conclusion our study has provided evidence that the mucus barrier, an important component of the preepithelial barrier, is altered in CD patients. We speculate that the resulting decreased capacity of the mucus barrier to repel luminal contents because of low hydrophobicity and to act as a "closing seal"[22] may potentially contribute to the increased intestinal permeability characteristic of $\mathrm{CD}$. Although the model of intestinal hydrophobicity as a "closing seal" has as yet to be proven, it has been proven that this bio-physical property represents a valid criterion for assessing the protective function of the mucus layer. Studies in the animal and pilot studies in humans suggest that mucus layer hydrophobicity can be increased by oral administration of phospholipids [36], and this may prove of value as adjuvant treatment in $\mathrm{CD}$ patients with incomplete response to GFD. Our study has also confirmed regional differences in surface hydrophobicity of the mucus layer of control subjects, and has provided reference values that may be of value for further comparative studies in disease conditions other than $\mathrm{CD}$.

\section{Acknowledgements}

The goniometer was a generous gift of A.I.C. (Italian Celiac Association) Lombardia

\section{Author details}

${ }^{1}$ Gastroenterology Unit: Spedali Civili and University. Piazzale Spedali Civili 1. 25123 Brescia. Italy. ${ }^{2}$ Histopathology: Spedali Civili and University. Piazzale Spedali Civili 1. 25123 Brescia. Italy.

\section{Authors' contributions}

SB carried out all goniometric measurements and contributed to planning the study, and to analysis and expression of results

FL carried out all endoscopies, provided all bioptic material for the study and contributed to planning of the study.

BZ contributed to identification and selection of the patients and controls, and contributed to analysis and expression of results

CR contributed to identification and selection of the patients and controls, and contributed to analysis and expression of results

W examined and classified all endoscopic biopsies.

AL planned the study, contributed to analysis and expression of results and wrote and edited the manuscript.

All authors read and approved the final manuscript

\section{Competing interests}

The authors declare that they have no competing interests.

Received: 23 May 2011 Accepted: 7 November 2011

Published: 7 November 2011

\section{References}

1. Turner JR: Intestinal mucosal barrier function in health and disease. Nat Rev Immunol 2009, 9:799-809.

2. Hills BA, Butler BD, Lichtenberger LM: Gastric mucosal barrier: hydrophobic lining to the lumen of the stomach. Am J Physiol 1983, 244 : G561-G568.

3. Goddard PJ, Kao YC, Lichtenberger LM: Luminal surface hydrophobicity of canine gastric mucosa is dependent on a surface mucus gel. Gastroenterology 1990, 98:361-370.

4. Specian RD, Oliver MG: Functional biology of intestinal goblet cells. Am J Physiol 1991, 260:C183-C193.

5. Arrieta $M C$, Bistritz L, Meddings JB: Alterations in intestinal permeability. Gut 2006, 55:1512-1520.

6. Smecuol E, Bai JC, Vazquez H, Kogan Z, Cabanne A, Niveloni S, Pedreira S, Boerr L, Maurino E, Meddings JB: Gastrointestinal permeability in celiac disease. Gastroenterology 1997, 112:1129-1136.

7. Fasano A, Not T, Wang W, Uzzau S, Berti I, Tommasini A, Goldblum SE: Zonulin, a newly discovered modulator of intestinal permeability, and its expression in coeliac disease. Lancet 2000, 355:1518-1519.

8. Dewar D, Pereira SP, Ciclitira PJ: The pathogenesis of coeliac disease. Int J Biochem Cell Biol 2004, 36:17-24.

9. Lichtenberger $L M$ : The hydrophobic barrier properties of gastrointestinal mucus. Annu Rev Physiol 1995, 57:565-583.

10. Mack DR, Neumann AW, Policova Z, Sherman PM: Surface hydrophobicity of the intestinal tract. Am J Physiol 1992, 262:G171-G177.

11. Spychal RT, Goggin PM, Marrero JM, Saverymuttu SH, Yu CW, Corbishley CM, Maxwell JD, Northfield TC: Surface hydrophobicity of 
gastric mucosa in peptic ulcer disease. Relationship to gastritis and Campylobacter pylori infection. Gastroenterology 1990, 98:1250-1254.

12. Goggin PM, Marrero JM, Spychal RT, Jackson PA, Corbishley CM, Northfield TC: Surface hydrophobicity of gastric mucosa in Helicobacter pylori infection: effect of clearance and eradication. Gastroenterology 1992, 103:1486-1490

13. Lugea A, Antolin M, Mourelle M, Guarner F, Malagelada JR: Deranged hydrophobic barrier of the rat gastroduodenal mucosa after parenteral nonsteroidal anti-inflammatory drugs. Gastroenterology 1997. 112:1931-1939.

14. Tatsumi Y, Lichtenberger LM: Molecular association of trinitrobenzenesulfonic acid and surface phospholipids in the development of colitis in rats. Gastroenterology 1996, 110:780-789.

15. Dial EJ, Romero JJ, Villa X, Mercer DW, Lichtenberger LM: Lipopolysaccharide-induced gastrointestinal injury in rats: role of surface hydrophobicity and bile salts. Shock 2002, 17:77-80

16. Lugea A, Salas A, Casalot J, Guarner F, Malagelada JR: Surface hydrophobicity of the rat colonic mucosa is a defensive barrier against macromolecules and toxins. Gut 2000, 46:515-521.

17. Lanzini A, Lanzarotto F, Villanacci V, Mora A, Bertolazzi S, Turini D, Carella G, Malagoli A, Ferrante G, Cesana BM, Ricci C: Complete recovery of intestinal mucosa occurs very rarely in adult coeliac patients despite adherence to gluten-free diet. Aliment Pharmacol Ther 2009, 29:1299-1308.

18. Zanini B, Lanzarotto F, Mora A, Bertolazzi S, Turini D, Cesana B, Donato F, Ricci C, Lonati F, Vassallo F, Scarcella C, Lanzini A: Five year time course of celiac disease serology during gluten free diet: results of a community based "CD-Watch" program. Dig Liver Dis 2010, 42:865-870.

19. Marsh MN: Gluten, major histocompatibility complex, and the small intestine. A molecular and immunobiologic approach to the spectrum of gluten sensitivity ('celiac sprue'). Gastroenterology 1992, 102:330-354.

20. Oberhuber G, Granditsch G, Vogelsang H: The histopathology of coeliac disease: time for a standardized report scheme for pathologists. Eur J Gastroenterol Hepatol 1999, 11:1185-1194.

21. Spychal RT, Marrero JM, Saverymuttu SH, Northfield TC: Measurement of the surface hydrophobicity of human gastrointestinal mucosa. Gastroenterology 1989, 97:104-111.

22. Ehehalt R, Braun A, Karner M, Fullekrug J, Stremmel W: Phosphatidylcholine as a constituent in the colonic mucosal barrier-physiological and clinical relevance. Biochim Biophys Acta 2010, 1801:983-993.

23. Adamson AW: Physical chemistry of surfaces, Wiley, 41982

24. Hills BA: Gastric mucosal barrier: stabilization of hydrophobic lining to the stomach by mucus. Am J Physiol 1985, 249:G342-G349.

25. Smecuol E, Vazquez H, Sugai E, Niveloni S, Pedreira S, Cabanne A, Fiorini A, Kogan Z, Maurino E, Meddings J, Bai JC: Sugar tests detect celiac disease among first-degree relatives. Am J Gastroenterol 1999, 94:3547-3552.

26. Duerksen DR, Wilhelm-Boyles C, Parry DM: Intestinal permeability in longterm follow-up of patients with celiac disease on a gluten-free diet. Dig Dis Sci 2005, 50:785-790

27. Lammers KM, Lu R, Brownley J, Lu B, Gerard C, Thomas K, Rallabhandi P, Shea-Donohue T, Tamiz A, Alkan S, Netzel-Arnett S, Antalis T, Vogel SN, Fasano A: Gliadin induces an increase in intestinal permeability and zonulin release by binding to the chemokine receptor CXCR3. Gastroenterology 2008, 135:194-204.

28. Matysiak-Budnik T, Candalh C, Dugave C, Namane A, Cellier C, CerfBensussan N, Heyman M: Alterations of the intestinal transport and processing of gliadin peptides in celiac disease. Gastroenterology 2003, 125:696-707.

29. Hackelsberger A, Platzer U, Nilius M, Schultze V, Gunther T, DominguezMunoz JE, Malfertheiner P: Age and Helicobacter pylori decrease gastric mucosal surface hydrophobicity independently. Gut 1998, 43:465-469.

30. Ciacci C, Di VD, Seth R, Insabato G, Mazzacca G, Podolsky DK, Mahida YR: Selective reduction of intestinal trefoil factor in untreated coeliac disease. Clin Exp Immunol 2002, 130:526-531.

31. Vecchi M, Torgano G, de FR, Tronconi S, Agape D, Ronchi G: Evidence of altered structural and secretory glycoconjugates in the jejunal mucosa of patients with gluten sensitive enteropathy and subtotal villous atrophy. Gut 1989, 30:804-810.

32. Nusrat A, von Eichel-Streiber C, Turner JR, Verkade P, Madara JL, Parkos CA Clostridium difficile toxins disrupt epithelial barrier function by altering membrane microdomain localization of tight junction proteins. Infect Immun 2001, 69:1329-1336
33. McNamara BP, Koutsouris A, O'Connell CB, Nougayrede JP, Donnenberg MS, Hecht G: Translocated EspF protein from enteropathogenic Escherichia coli disrupts host intestinal barrier function. J Clin Invest 2001, 107:621-629.

34. Qin X, Caputo FJ, Xu DZ, Deitch EA: Hydrophobicity of mucosal surface and its relationship to gut barrier function. Shock 2008, 29:372-376.

35. Chung C, van HL, Policova Z, Beharry S, Sherman PM, Neumann AW, Durie P: Surface hydrophobicity is increased in the ileum and proximal colon of cystic fibrosis mice. Pediatr Res 1999, 46:174-178.

36. Gibson PR, Muir JG: Reinforcing the mucus: a new therapeutic approach for ulcerative colitis? Gut 2005, 54:900-903.

\section{Pre-publication history}

The pre-publication history for this paper can be accessed here: http://www.biomedcentral.com/1471-230X/11/119/prepub

doi:10.1186/1471-230X-11-119

Cite this article as: Bertolazzi et al:: Bio-physical characteristics of gastrointestinal mucosa of celiac patients: comparison with control subjects and effect of gluten free diet-. BMC Gastroenterology 2011 11:119.

\section{Submit your next manuscript to BioMed Central and take full advantage of:}

- Convenient online submission

- Thorough peer review

- No space constraints or color figure charges

- Immediate publication on acceptance

- Inclusion in PubMed, CAS, Scopus and Google Scholar

- Research which is freely available for redistribution 